\title{
Lost feeling of ownership of one's mental states: the importance of situating patient R.B.'s pathology in the context of contemporary theory and empiricism
}

Stanley B. Klein

To cite this article: Stanley B. Klein (2016) Lost feeling of ownership of one's mental states: the importance of situating patient R.B.'s pathology in the context of contemporary theory and empiricism, Philosophical Psychology, 29:4, 490-493, DOI: 10.1080/09515089.2015.1126815

To link to this article: http://dx.doi.org/10.1080/09515089.2015.1126815

Published online: 15 Apr 2016.

Submit your article to this journal ¿

Џ Article views: 58

Q View related articles ¿

View Crossmark data ¿ 


\title{
Lost feeling of ownership of one's mental states: the importance of situating patient R.B.'s pathology in the context of contemporary theory and empiricism
}

\author{
Stanley B. Klein \\ Department of Psychological and Brain Sciences, University of California, Santa Barbara, CA, USA
}

In her paper "Memory and Mineness in Personal Identity," Rebecca Roache (this issue) makes a number of claims about the nature of memory, the nature of self, and the relation between the two. In particular, she argues that Klein and Nichols's (2012) treatment of Locke's connectivity account of self and memory rests on an "implausible," "unsupported," and "untenable" interpretation of patient R.B.'s memory problems.

I have no interest in debating Roache's views on the relation between self and memory. Serious treatment of what currently is known about that relation easily would exceed the space provided for commentary. Suffice it to say that psychological discoveries over the past 60 years reveal that no simple account is capable of being fitted to Locke's thesis: the relation, as now understood, consists in a complex interplay between different aspects of the self (for a review, see Klein, 2012; Klein \& Gangi, 2010) and different types of memory (e.g., Kopelman, Wilson, \& Baddeley, 1989; Tulving 1985). These issues are discussed in Klein (2014a).

In what follows, I focus on Roache's claim that patient R.B.'s report of losing possessory custody of mental content is not sanctioned by the language he uses to relate his phenomenology. I present evidence (some new) supporting Klein and Nichols's interpretation of patient R.B.s ownership pathology and, in the process, argue that Roache's re-analysis is unsupported by theory and evidence.

\section{Ways of apprehending one's intentional objects: first-person perspective versus personal ownership}

Roache appears to subscribe to the idea that there are neural systems dedicated to the storage and retrieval of memories (allowing for modification following initial storage; e.g., Schacter, 1995). Accordingly, first-person experience of retrieved content is sufficient to designate that content as a memory.

This view - that memory is retrieved into awareness "as memory" (the so-called "received view") however, is called into question by recent findings suggesting that what is retrieved is not memory per se. Rather, it is system-agnostic content which can acquire the status of "memory" provided certain mental acts are performed after that content has been retrieved (for fuller discussion see Klein, 2015; see also Dalla Barba, 2002; Markowitsch \& Staniloiu, 2013; Moyal-Sharrock, 2009; Ranganath $\&$ Ritchet, 2012). For example, to experience retrieved content as an act of recollection (i.e., episodic memory), the content must be conjoined at retrieval with the pre-reflective feeling that it belongs to me (e.g., James, 1890; Klein, 2013, forthcoming; Tulving, 2005). 
This confusion between episodic memory as given to consciousness and episodic memory as created by consciousness (via application of felt ownership to retrieved content) is reflected in Roache's claim that the fact that R.B.

can see the scene in my head. I'm studying with friends in the lounge at my residence hall. I am able to re-live it. I have a feeling ... a sense of being at there, at MIT, in the lounge.

creates problems for any account of his pathology as a failure to maintain first-person perspective. I agree. But we did not claim R.B. lacked first-person perspective on his mental occurrences. In the remainder of the quote (which Roache does not present), R.B. comments: "But it doesn't feel like I own it. It's like I'm imagining, re-living the experience, but it was described by someone else."

Here, as in many places in the transcripts, R.B. is emphatic that although he experiences retrieved content (he describes it as "like watching a film"), he lacks any accompanying non-inferential feeling that he personally witnessed the events from which the content derived ("I didn't make it" [i.e., the film]). And, as previously noted, conscious apprehension of an intentional object (e.g., Brentano, 1995), absent a feeling of ownership, renders an experience "memory-like" but not recollective. This, as we argued in Klein and Nichols (as well as many subsequent publications; e.g., Klein, 2013, 2014b, 2015, forthcoming) is the crux of R.B.'s "memory" problem.

Klein and Nichols (2012) share some of the responsibility for what Roache sees as conceptual inconsistency. We were struggling to understand what, at the time, seemed a novel and bizarre neuro-cognitive impairment (but see section 2). Accordingly, we took pains to present quotes (selected from more than 20 pages of transcripts) that we felt highlighted the nature R.B.'s pathology. However, our attempt to make sense of R.B.'s issues likely resulted in some expositional slippage.

\section{Situating R.B.'s memory dysfunction in psychological theory}

In subsequent papers (all cited by Roache; e.g., Klein, 2013, 2015, forthcoming), I more securely positioned R.B.'s problem within contemporary psychological accounts of memory (e.g., Dalla Barba, 2002; Moulin, Souchay, \& Morris 2013; Tulving, 1985; Wheeler, Stuss, \& Tulving, 1997). This enabled me to present a conceptually rigorous and theoretically grounded picture of R.B. as a person suffering a dissociation between first-person acquaintance with occurrent mental content and felt ownership of that content (in this way, he is like the schizophrenic who experiences a thought but feels that it was authored by someone else).

R.B.'s reported experience is consistent with recent theory that memory is not just the content of one's experience, but rather the manner in which that content is consciously apprehended (for fuller treatment see Dalla Barba, 2002; Klein, 2015; Tulving, 1985). The same (or substantially the same) content can be experienced as a belief, attitude, goal, thought, imagination, memory, and so forth. To qualify as recollection, content must be conjoined with a feeling that it belongs to me (e.g., Klein, 2013).

On this view-which is found in many philosophical treatments of memory (e.g., Hume, Locke, Russell; for a review, see Klein, 2015) -first-person perspective is a necessary but not sufficient condition for having a memory experience. What also is required is that the content be experienced as mine (e.g., James, 1890; Klein, 2013; Markowitsch \& Staniloiu, 2013). Convergent support is found in recent radiological and lesion studies showing that different neural systems appear to be responsible for storage of content and its experience as personally owned (for a review, see Klein, 2015).

Although we were unaware at the time, malfunction of the mechanism(s) responsible for feeling that one owns one's mental states is a well-documented clinical phenomenon-e.g., anosagnosia, somatoparaphrenia, depersonalization, schizophrenic thought insertion, craniopargus, hallucinations (for a review, see Klein, forthcoming). There even are reports (other than that of patient R.B.) in which loss of ownership targets "memory." For example, during the acute phase of depersonalization, individuals report that what normally would be taken as memory feels like an alien intrusion (Sierra, Baker, Medford, \& David, 2005). Talland (1964) presents the case of a patient who accurately could describe content retrieved into consciousness, but was unable to experience that content as his own (despite its subjectively felt location in his head). Additional cases can be found in Klein (2015). 
In short, R.B.'s felt loss of ownership can be situated within a well-developed taxonomic and theoretical framework (e.g., Klein, 2013, forthcoming; see also Markowitsch \& Staniloiu, 2013; Ranganath \& Ritchet, 2012). While such positioning does not guarantee correctness of placement, it does suggest that assignment is not easily undermined by purely conceptual analysis.

\section{Some additional quotes that illuminate R.B.'s pathology}

We believed the quotes in Klein and Nichols nicely captured R.B.'s memory problem. Apparently we were wrong. Below I present a few additional quotes that I hope show that R.B's phenomenology consists in the lost ownership of, rather than first-person perspective on, content retrieved into consciousness:

My memories [R.B.'s emphasis] do not feel in any way like they're my memories. They feel like facts I know, like that Washington was the first president. I can infer that they're about me because I know what they're about. ... It doesn't take much (inference). But even then, when I figure out a memory is about me it doesn't help me take ownership. It feels like third party ... like it belongs to some else. (Parentheses added for clarification based on discussions with R.B.)

Here is a longer quote in "question/answer" format:

S.B.K.: You say you own your memories from after the accident. What do you mean by "owning” your memories?

R.B.: They feel like things that happened to me. I can see them (in my head).... They feel like part of my life ... my past ... things that happened to me. I was there. I guess that's what I mean by owning them (memory). They're mine, my past ... not something I just know about. ... I was there ... lived through it.

S.B.K.: And memories from before the accident-you don't feel like you own them?

R.B.: $\quad$ Right. I see them play in my head. Like watching a movie. I watch them, they fit (with what I know about my past), but I don't own them. ... I don't feel like I was there (when the events happened). I know they must be mine, must have happened to me, but I feel like I'm watching a movie about me that I didn't make (Parentheses added for clarification-based on discussions with R.B.).

In these quotes (as well as many others), R.B. is insistent that he experiences first-person awareness of his intentional objects. What he reports missing is any direct, pre-reflective feeling of owning the objects that, of ontological necessity, he must have authored.

\section{Several additional problems for Roache's conceptual re-analysis}

Roache fails to report an important quote from Klein and Nichols (repeated in other publications; e.g., Klein, 2013, 2014b) that, I believe, creates serious problems for her thesis that R.B.'s "memories" are more in the nature of "imagination":

When I did 'take ownership' of a memory, it was actually quite isolated. A single memory I might own, yet another memory connected to it I would not own. It was a startling experience to have no rhyme or reason to which memories I slowly took ownership of, one at a time at random over a period of weeks and months.... What happened over the coming months ... was interesting. Every once in a while, I would suddenly think about something in my past and I would 'own' it. That was indeed something 'I' had done and experienced. Over time, one by one, I would come to 'own' different memories. Eventually, after perhaps eight months or so, it seemed as if it was all owned ... as if once enough individual memories were owned, it was all owned. For example, the MIT memory, the one in the lounge ... I now own it. It's clearly part of my life, my past.

While people can (and often do) confuse memory and imagination, for Roache's argument to gain traction, she would have to allow that an unprecedented number of imaginations are transformed in a matter of months into the entire corpus of R.B.'s pre-morbid recollections. Such a finding would constitute a unique (and, at present, theoretically inexplicable) occurrence in the annals of neurology. In contrast, the interpretation I champion fits comfortably within existing taxonomy of ownership pathology and theory about episodic memory (e.g., Klein, 2013, forthcoming; Markowitsch \& Staniloiu, 2013; Moulin, Souchay, \& Morris, 2013). 
Second, R.B. did maintain possessory custody of retrieved content from his post-morbid life. Accordingly, he was quite capable of distinguishing content he felt to be memories from content that he did not. Finally, as noted in Klein and Nichols, many (i.e., those for which corroboration was possible) of R.B.'s alleged “imaginations" were validated by third party observers as actual life occurrences.

\section{Final thoughts}

In summary, Roache makes a number assertions about the "real meaning" of R.B.'s phenomenological reports which, in the context of contemporary memory theory, appear questionable. It is well-known the reliance on language to convey one's phenomenology is fraught with difficulty-e.g., the lack of terms capable of reflecting the fullness of experience, the influence of social convention on word selection, and so forth (see Sokolowski, 1999). It is not surprising, therefore, that, from a purely analytic perspective, R.B.s description of his pathology sometimes appears inconsistent. But, when situated within the context of current theory and empiricism, his reports strongly suggest that-despite some expositional looseness-what he (consistently) says accurately captures his pathology as experienced.

\section{References}

Brentano, F. (1995). Descriptive psychology (B. Müller, Trans.). London: Routledge.

Dalla Barba, G. (2002). Memory, consciousness and temporality. Norwell, MA: Kluwer.

James, W. (1890). Principles of psychology. New York, NY: Holt.

Klein, S. B. (2012). The self and its brain. Social Cognition, 30, 474-516.

Klein, S. B. (2013). Making the case that episodic recollection is attributable to operations occurring at retrieval rather than to content stored in a dedicated subsystem of long-term memory. Frontiers in Behavioral Neuroscience, 7, 3.

Klein, S. B. (2014a). Sameness and the self: Philosophical and psychological considerations. Frontiers in Psychology: Perception, 5, 29.

Klein, S. B. (2014b). Autonoesis and belief in a personal past: An evolutionary theory of episodic memory indices. Review of Philosophy and Psychology, 5, 427-447.

Klein, S. B. (2015). What memory is. WIREs Cognitive Science, 6, 1-38.

Klein, S. B. (forthcoming). The feeling of personal ownership of one's mental states: A conceptual argument and empirical evidence for an essential, but underappreciated, mechanism of mind. Psychology of Consciousness: Theory, Practice, and Research.

Klein, S. B., \& Gangi, C. (2010). The multiplicity of self: Neuropsychological evidence and its implications for the self as a construct in psychological research. Annals of the New York Academy of Sciences, 1191, 1-15.

Klein, S. B., \& Nichols, S. (2012). Memory and the sense of personal identity. Mind, 121, 677-702.

Kopelman, M. D., Wilson, B. A., \& Baddeley, A. D. (1989). The autobiographical memory interview: A new assessment of autobiographical and personal semantic memory in amnesic patients. Journal of Clinical and Experimental Neuropsychology, 11, 724-744.

Markowitsch, H. J., \& Staniloiu, A. (2013). The impairment of recollection in functional amnesic states. Cortex, 49, 1494-1510.

Moulin, C. J. A., Souchay, C., \& Morris, R. G. (2013). The cognitive neuropsychology of Recollection. Cortex, 49, $1445-1451$.

Moyal-Sharrock, D. (2009). Wittgenstein and the memory debate. New Ideas Psychology, 27, 213-227.

Ranganath, C., \& Ritchet, M. (2012). Two cortical systems for memory-guided behavior. Nature Reviews: Neuroscience, $13,713-726$.

Roache, R. (this issue). Memory and mineness in personal identity. Philosophical Psychology.

Schacter, D. L. (1995). Memory distortion: How minds, brains, and societies reconstruct the past. Cambridge, MA: Harvard University Press.

Sierra, M., Baker, D., Medford, N., \& David, A. S. (2005). Unpacking the depersonalization syndrome: An exploratory factor analysis on the Cambridge Depersonalization Scale. Psychological Medicine, 35, 1523-1532.

Sokolowski, R. (1999). Introduction to phenomenology. New York, NY: Cambridge University Press.

Talland, G. A. (1964). Self-reference: A neglected component in remembering. American Psychologist, 19, 351-353.

Tulving, E. (1985). Memory and consciousness. Canadian Psychology/ Psychologie Canadienne, 26, 1-12.

Tulving, E. (2005). Episodic memory and autonoesis: Uniquely human? In H. S. Terrace, \& J. Metcalfe (Eds.), The missing link in cognition: Origins of self-reflective consciousness (pp. 3-56). Oxford: Oxford University Press.

Wheeler, M. A., Stuss, D. T., \& Tulving, E. (1997). Toward a theory of episodic memory: The frontal lobes and autonoetic consciousness. Psychological Bulletin, 121, 331-354. 